OPEN ACCESS

Edited by:

Joseph G. Dubrovsky, National Autonomous University

of Mexico, Mexico

Reviewed by:

Alexis Maizel,

Universität Heidelberg, Germany

Tom Beeckman,

Ghent University, Belgium

*Correspondence:

Frank Hochholdinger

hochholdinger@uni-bonn.de

Peng Yu

yupeng@uni-bonn.de

Specialty section:

This article was submitted to Plant Development and EvoDevo,

a section of the journal

Frontiers in Plant Science

Received: 29 October 2018

Accepted: 08 January 2019

Published: 12 February 2019

Citation:

Kortz A, Hochholdinger F and Yu P (2019) Cell Type-Specific Transcriptomics of Lateral Root

Formation and Plasticity.

Front. Plant Sci. 10:21

doi: $10.3389 /$ fpls.2019.00021

\section{Cell Type-Specific Transcriptomics of Lateral Root Formation and Plasticity}

\author{
Annika Kortz, Frank Hochholdinger* and Peng Yu* \\ INRES, Institute of Crop Science and Resource Conservation, Crop Functional Genomics, University of Bonn, Bonn, \\ Germany
}

Lateral roots are a major determinant of root architecture and are instrumental for the efficient uptake of water and nutrients. Lateral roots consist of multiple cell types each expressing a unique transcriptome at a given developmental stage. Therefore, transcriptome analyses of complete lateral roots provide only average gene expression levels integrated over all cell types. Such analyses have the risk to mask genes, pathways and networks specifically expressed in a particular cell type during lateral root formation. Cell type-specific transcriptomics paves the way for a holistic understanding of the programming and re-programming of cells such as pericycle cells, involved in lateral root initiation. Recent discoveries have advanced the molecular understanding of the intrinsic genetic control of lateral root initiation and elongation. Moreover, the impact of nitrate availability on the transcriptional regulation of lateral root formation in Arabidopsis and cereals has been studied. In this review, we will focus on the systemic dissection of lateral root formation and its interaction with environmental nitrate through cell type-specific transcriptome analyses. These novel discoveries provide a better mechanistic understanding of postembryonic lateral root development in plants.

Keywords: fluorescence activated cell sorting (FACS), laser capture microdissection (LCM), lateral root, pericycle, transcriptome

\section{INTRODUCTION}

A key strategy of plants to adapt to changing moisture and nutrient availability in soil is the formation of a postembryonic root system. Among postembryonic root types, lateral roots are all roots that emerge from other roots. Highly branched lateral roots absorb most of the soil resources via their large root surface (Yu et al., 2016b). The genetic control of lateral root development in the dicot model plant Arabidopsis (Lavenus et al., 2013) and in monocot cereals (Yu et al., 2016b) has recently been reviewed. RNA sequencing (RNA-seq) has been widely adopted to study the transcriptomic landscape of organ and tissue development in plants (Stelpflug et al., 2016). Transcriptome analysis of lateral roots has been shown to be distinct from that of parent roots in both maize and rice, supporting the notion that fine lateral roots and thicker roots are functionally different (Gutjahr et al., 2015; Yu et al., 2018). Comparative transcriptome analyses of wild-type and mutant root systems in maize and rice have revealed molecular functions involved in auxin signaling and cell cycle regulation during lateral root formation (Zhang et al., 2014; Zhao et al., 2015). However, organs or tissues are composite structures consisting of multiple cell types with different biological functions and thus disparate transcriptome profiles (Schnable et al., 2004). 
Transcriptomic analyses of single tissues, single cell types and in its extreme, single cells, have been successfully introduced in medical research and have subsequently been adopted in plant science (reviewed in: Gautam and Sarkar, 2015). There are two main systems that have been utilized in sampling single cell types and single cells. First, fluorescence activated cell sorting (FACS) was initially introduced as a tool to analyze mammalian blood cells (Hulett et al., 1969). This technique requires that cells flow in a fluid stream through the focus of a light source, where detectors can distinguish between different properties of these cells (Galbraith, 2010). Subsequently cells are separated either based on their endogenous or artificially added fluorochromes, or by metric properties estimated from their absorption and scattering behavior (Galbraith, 2010). By using multiple cell type-specific reporters such as green or yellow fluorescent proteins, distinct cell types of a single tissue can be sampled separately (Iyer-Pascuzzi and Benfey, 2010). A drawback of FACS is the requirement of cell type-specific marker lines, which are only available for selected model organisms. Moreover, these marker lines must be protoplasted by enzymatic digestion of the surrounding cell walls, to allow subsequent separation of different types of cells by the FACS system (Galbraith, 2010).

The second technique used for cell type-specific and single cell isolation is laser capture microdissection (LCM). This approach was initially developed to isolate specific tumor cells from infested tissue without compromising their DNA, RNA, and protein integrity (Emmert-Buck et al., 1996). During LCM, the cells of interest are visualized and selected through a light microscope and subsequently excised with a pulsed infrared laser (Nelson et al., 2006). This allows the isolation of specific cells from complex tissue samples comprising distinct cell types (Gautam and Sarkar, 2015). In contrast to FACS, LCM is not confined to cell suspension. Nevertheless, an elaborate sample preparation is still needed to ensure the high quality and integrity of the cells under analysis (Ludwig and Hochholdinger, 2014). The application of these two cell sorting techniques, in combination with downstream transcriptome analyses in lateral root research, will be summarized in the following chapters of this review.

\section{CELL TYPE-SPECIFIC TRANSCRIPTOMICS TARGETING LATERAL ROOT FORMATION IN ARABIDOPSIS}

In Arabidopsis, only cells of the pericycle cell layer divide and contribute to lateral root formation (van Norman et al., 2013). Therefore, the pericycle is the most promising target of cellspecific transcriptomics to study lateral root development in this species. The first cell type-specific transcriptome atlas of the Arabidopsis primary root was created by a combination of FACS and microarray experiments (Birnbaum et al., 2003). In this study, stele, endodermis, endodermis plus cortex, epidermis, and lateral root cap cells from the meristematic zone, elongation zone, and differentiation zone were separated and the transcriptomes of these cell and tissue types were analyzed (Birnbaum et al., 2003). This approach did not directly aim at deciphering lateral root development because the pericycle, as the origin of lateral roots, was not separately collected but included in the stele tissue sample. However, it paved the way for cell type-specific transcriptomic analyses and served as a valuable data source for further analyses. To further refine the resolution of cell typespecific expression in roots, the transcriptomes of 14 root cell types, including lateral root primordia, whole pericycle, phloem pole pericycle cells, and xylem pole pericycle cells, were analyzed separately for thirteen regions along the longitudinal root axis in a follow up study. This allowed detecting expression variation between different developmental stages by the combination of manual dissection, FACS and transcriptome profiling via microarray (Brady et al., 2007).

In Arabidopsis, lateral roots initiate from pericycle cells located at the xylem poles (Dolan et al., 1993; Parizot et al., 2008). The usage of two distinct marker lines for xylem and phloem pole cells in FACS experiments enabled the search for variations of the transcriptomic landscape within these distinct pericycle cell types. With this setup, the auxin biosynthetic genes CYP79B2, CYP79B3, SUPERROOT1, and SUPERROOT2 were found to be enriched in lateral root primordia and phloem pole pericycle cells, while tryptophan-dependent auxin biosynthetic genes were enriched in the lateral root primordia and in pericycle cells (Brady et al., 2007). Moreover, FACS sorting of xylem pole pericycle cells of Arabidopsis and subsequent transcriptome analyses, resulted in 1,920 genes differentially expressed at different stages of mitosis (De Smet et al., 2008). Fifteen of these genes were identified as putative key regulators of asymmetric cell division and as being involved in the specification of cell fate during the initiation of lateral roots. Among those, ARABIDOPSIS CRINKLY4 (ACR4, AT3G59420), which encodes a membranelocalized receptor-like kinase, is specifically expressed in the daughter cells, which arose from the first and second asymmetric division of the pericycle cells. This suggests a role of ACR4 in the regulation of pericycle cell division during the initiation of lateral roots and inhibition of division of neighboring cells (De Smet et al., 2008).

In an effort to utilize transcriptomic data from multiple root cell types generated in different experiments, a spreadsheet application termed VisuaLRTC has been introduced (Parizot et al., 2010). Using this tool, the authors explored the expression of members of the Aux/IAA, AUXIN RESPONSE FACTOR (ARF) and LATERAL ORGAN BOUNDARIES DOMAIN (LBD) families, which are involved in auxin signal transduction. The authors applied multiple criteria including for instance SLR-1 and ARF7-ARF19 dependency of expression, or xylem or phloem pole pericycle expression (Parizot et al., 2010). Through this approach, the authors detected known regulators of auxin signal transduction such as IAA29, IAA5, IAA11, IAA2, LBD17, and $L B D 33$ as promising candidates for lateral root development (Parizot et al., 2010). Moreover, they discovered 211 additional candidate genes for lateral root development including known regulators of lateral root development (Parizot et al., 2010). Furthermore, they identified 19 pericycle-specific genes. Most of them were of unknown function and nearly all were down 
regulated by auxin (Parizot et al., 2010). In another in silico transcriptome analysis of pericycle cell populations and their associated vascular phloem or xylem poles tissues, only minorities of genes were either enriched in phloem pole or xylem pole pericycle cells (Parizot et al., 2012). Furthermore, these researchers observed a substantial overlap between the expression of pericycle cells and their respective adjacent vasculature tissue. In phloem pole pericycle and phloem pole cells, this overlap was higher than in xylem pole pericycle cells and xylem pole cells. The authors explained this observation by the meristematic identity of the xylem pole pericycle cells, which distinguishes their function from the adjacent phloem pole pericycle cells (Parizot et al., 2012).

\section{CELL TYPE-SPECIFIC TRANSCRIPTOMICS TARGETING LATERAL ROOT FORMATION IN MONOCOTS}

In contrast to Arabidopsis, lateral root primordia of maize and rice are formed from two different cell types: pericycle and endodermis cells (Bell and McCully, 1970; Clowes, 1978). Furthermore, in maize, lateral roots emerge from phloem pole pericycle cells compared to xylem pole pericycle cells in Arabidopsis [reviewed in: Hochholdinger and Zimmermann (2008)].

In rice (Oryza sativa), the combination of LCM and microarray profiling was used to create a cell type-specific transcriptome atlas of 40 cell types from shoot, root and germinating seeds at several developmental stages. The aim of this study was to identify cell type-specific genes and gene classes as well as cell-specific promoter motifs (Jiao et al., 2009). Through the application of LCM-assisted microarray experiments the transcriptome of three cell type clusters: (1) epidermis, exodermis and sclerenchyma, (2) cortex, and (3) endodermis, pericycle, and stele termed endstele were compared in rice crown roots, at different developmental stages. In total, 232 genes were up regulated in cluster (3) comprising endodermis, pericycle and stele cells in comparison to the other two clusters and in comparison to stele tissue collected further away from the root tip (Takehisa et al., 2012). 71 genes associated with cell division and elongation as well as numerous transcription factors were only expressed in the region of 1-3 $\mathrm{mm}$ from the root tip emphasizing a role particularly in priming and initiation of lateral roots (Takehisa et al., 2012). An AP2/EREBP gene (Os07g0669500), which was assorted to this group, is a homolog of Arabidopsis gene PUCHI. The PUCHI gene is involved in specific patterning of cell division during the early stages of lateral root primordium development (Hirota et al., 2007). Another member of this gene cluster (Os03g0659700) shares similarities with Arabidopsis AS2-LIKE 18 (ASL18/LBD 16), ASL16/LBD29, ASL20/LBD18, and rice CROWN ROOTLESS 1/ADVENTITIOUS ROOTLESS 1 (CRL1/ARL1), which are linked to lateral root initiation (Inukai et al., 2005; Okushima et al., 2007; Lee et al., 2009;
Coudert et al., 2015). In addition, the homolog (Os09g0531600) of the Arabidopsis gene LATERAL ROOT PRIMORDIUM 1, which has been previously linked to the early development of the lateral root meristem (Smith and Fedoroff, 1995), was specifically expressed in the endodermis, pericycle and stele cluster (Takehisa et al., 2012). Furthermore, the preferential expression of auxin biosynthesis and signaling-related genes in the endstele tissue that is positioned $1-3 \mathrm{~mm}$ away from the root tip was observed in this study, supporting the notion of an auxin-associated mechanisms of lateral root initiation similar to Arabidopsis (Takehisa et al., 2012).

In maize (Zea mays), LCM was utilized to isolate pericycle cells from primary roots of the lateral root deficient mutant rootless with undetectable meristem 1 (rum1) and subjecting them to a subsequent transcriptome comparison with wild type pericycle cells. In this study, 90 genes preferentially expressed in wild type and 73 genes preferentially expressed in rum 1 pericycle cells were identified (Woll et al., 2005). Among the annotated genes, genes involved in signal transduction, transcription, and cell cycle were identified, indicating a link between these protein coding genes and lateral root initiation (Woll et al., 2005). Two of the genes preferentially expressed in wild type pericycle cells were helix-loop-helix transcription factors (NP_194827.1 and AAO72577.1), known to control the proliferation and development of specific cell lineages (Heim et al., 2003) undermining their possible involvement in lateral root initiation. In this study, the gene Cyclin T2 (BAD17160.1), which is involved in the regulation of eukaryotic cell cycle progression was up regulated in wild type pericycle cells (Wang et al., 2004).

To survey the transcriptome of pericycle cells of the maize primary root before lateral root initiation, pericycle and non-pericycle cells isolated via LCM were compared (Dembinsky et al., 2007). This experiment resulted in the identification of 32 genes significantly higher expressed in pericycle cells compared to the non-pericycle cells (Dembinsky et al., 2007). These genes belonged to multiple functional classes including transcription, protein synthesis, disease/defense, signal transduction, metabolism, protein fate and subcellular localization. To identify genes preferentially expressed in pericycle cells that might not have been included in the $12 \mathrm{k}$ microarray chip used in this study, suppression subtractive hybridization (SSH) and sequencing of expressed sequence tags (ESTs) were performed (Dembinsky et al., 2007). SSH led to the identification and validation of seven genes preferentially expressed in pericycle cells belonging to the functional categories of protein synthesis, cellular transport, disease/defense, signal transduction and metabolism. Moreover, 377 ESTs were sequenced from pericycle and 324 from non-pericycle central cylinder cells. Among those, the category protein synthesis was overrepresented and the category cell fate was underrepresented in pericycle compared to non-pericycle central cylinder cells (Dembinsky et al., 2007).

To identify distinct and shared components of the lateral root initiation pathway in maize primary and adventitious roots, pericycle cells were isolated via LCM from the different root types at multiple time points using a lateral root inducible 
system (Jansen et al., 2013). The authors discovered a shared core regulation system between primary and adventitious roots. This regulatory system was shown to be enriched for genes of the functional categories DNA binding and microtubule movement, indicating functions in gene regulation and cell division (Jansen et al., 2013). Moreover, in this study 14 genes from monocot-specific gene families, which might be involved in the positioning of lateral root initiation, were discovered. These genes might be involved in the different positioning of lateral root founder cells between Arabidopsis and maize (Jansen et al., 2013). This analysis also led to the identification of root type-specific transcription factors, of the MYB and MYB-related, homeobox and bHLH families (Jansen et al., 2013). A comparative study of maize (Jansen et al., 2013) and previously published Arabidopsis (Vanneste et al., 2005; De Smet et al., 2008) transcriptome datasets led to the identification of a shared core set of 60 genes. Moreover, these authors compared the phloem pole pericycle cell transcriptome of maize with transcriptomic profiles of xylem and phloem pole pericycle cells in Arabidopsis (Jansen et al., 2013). They showed that multiple genes including the gene LBD16/ASL18 were underrepresented in phloem pole pericycle cells of Arabidopsis, while the corresponding orthologs were induced upon lateral root induction in phloem pole pericycle cells of maize (Jansen et al., 2013). These findings indicated a shared identity between xylem pole pericycle cells of Arabidopsis and phloem pole pericycle cells of maize (Jansen et al., 2013). In addition, the existence of a conserved regulatory network among maize and Arabidopsis was further substantiated by the observed intersection of expression profiles of auxin-related genes (Jansen et al., 2013).

\section{CELL TYPE-SPECIFIC RESPONSES TO NITRATE LINKED TO LATERAL ROOT FORMATION}

Lateral roots shape overall root architecture based on the availability of nutrients such as nitrate and phosphate (Araya et al., 2014; Péret et al., 2014). Genotypes with sparsely spaced and long lateral roots are optimal for nitrate acquisition, while genotypes with densely spaced and short lateral roots are optimal for phosphate acquisition in crops (Lynch, 2011, 2013). Cell type-specific experiments have been performed to uncover transcriptomic changes in different cell types, which might regulate the adaptation observed upon nitrate treatment. Cell type-specific transcriptome analyses showed that nitrogen responses are to a large extent cell type-specific (Gifford et al., 2008). One of these cell type-specific nitrogen response genes, $A R F 8$, which has been linked to root development before (Gutierrez et al., 2009), was induced in pericycle cells through nitrogen (Gifford et al., 2008). Furthermore, miR167a was down regulated in pericycle cells in response to nitrogen treatment, resulting in the up regulation of $A R F 8$, which is a target of miR167a (Gifford et al., 2008; Gutierrez et al., 2009).

Similarly, nitrate treatment induced the expression of the Auxin Receptor F-Box Protein 3 (AFB3), a target of miR393 in pericycle cells of Arabidopsis (Vidal et al., 2010). This suggests that both are part of a network regulating lateral root formation as a response to high nitrate availability. Later, it was demonstrated that $A F B 3$ regulates the expression of NAM/ATAF/CUC transcription factor NAC4 and DNA-bindingwith-one-finger $(D O F)$ transcription factor binding protein 4 (OBP4) upon nitrogen treatment (Vidal et al., 2013). This emphasizes the existence of a regulatory module, which acts downstream of an auxin signal leading to the initiation of lateral roots through regulation of cell cycle progression in the pericycle (Vidal et al., 2013). This is in line with previous reports of OBP4 gene function in cell cycle regulation in Arabidopsis (Skirycz et al., 2008).

By utilizing FACS and GFP marker lines specific to Arabidopsis xylem pole pericycle cells, it was possible to observe the response of this cell type under nitrate influence over a time period of $48 \mathrm{~h}$ (Walker et al., 2017). In this experiment, NITRITE REDUCTASE (NIA1) and other NITRATE TRANSPORTERS (NRT2.3 and NRT2.5) were down regulated in the pericycle as an immediate response to the treatment (Walker et al., 2017). In the same context, the gene SENESCENCE-ASSOCIATED GENE 21 (SAG21), which has been previously linked to regulation of lateral root development and biotic responses (Salleh et al., 2012), was shown to be down regulated in the pericycle cells as a late response to nitrogen (Walker et al., 2017). In contrast, WRKY75, previously reported to regulate lateral root development (Devaiah et al., 2007), was strongly and directly up regulated in pericycle cells upon nitrogen treatment (Walker et al., 2017). Through the utilization of FACS and GFP-tagged lines, an induction of TGA1, TGA4, NRT2.1, and NRT2.2 in pericycle cells in response to nitrate was observed, indicating a possible involvement in the regulation of nitrogen-induced lateral root initiation in Arabidopsis (Alvarez et al., 2014).

In maize phloem pole pericycle cells of shoot-borne brace roots, local high nitrate induces the expression of B-type cyclindependent kinases $(C D K B)$ and cyclin $B(C Y C B)$ genes, while simultaneously inhibiting the expression of Kip-related proteins (Yu et al., 2015). $C D K B$ and $C Y C B$ genes are positive regulators of cell cycle progression (Schnittger et al., 2002; Boudolf et al., 2004), while Kip-related proteins (KRPs) are repressors of the cell cycle (De Veylder et al., 2001), linking the observed expression pattern to a reactivation of the cell cycle in the pericycle ( $\mathrm{Yu}$ et al., 2015). Furthermore, local nitrate influence led to a strong up regulation of $Z m P I N 9$ in phloem pole cells compared to endodermis and pericycle cells, indicating that this protein serves in the transport of auxin to adjacent pericycle cells (Yu et al., 2015). While PIN-formed genes have for long been known as auxin efflux carriers (Gälweiler et al., 1998), similar cell typespecific findings in rice emphasize that these monocot-specific PIN formed genes might also regulate the formation of the complex root systems developed by monocots (Wang et al., 2009; Yu et al., 2015).

Cell type-specific transcriptomics also enables comparisons between similar cell types in different root types within a species. In maize, it was shown that some nitrate-dependent expression patterns are conserved between the different root types ( $\mathrm{Yu}$ et al., 2016a). Conversely, in brace roots the number of genes 
exclusively expressed in pericycle cells exceeded the amount of exclusively expressed genes in seedling root types under homogeneous low or local high nitrate conditions ( $\mathrm{Yu}$ et al., 2016a). This indicates a root type-specific regulation of these genes during early lateral root initiation as well as a different response to nitrate influence (Yu et al., 2016a). Multiple nitrateresponsive genes specific to brace roots were shown to be involved in the assembly of nucleosomes/chromatin and in the microtubule motor activity needed for the movement of these during mitosis (Yu et al., 2016a).

\section{CONCLUSION AND PROSPECTS}

Tissue and cell type-specific transcriptomics have promoted the understanding of the molecular networks involved in lateral root formation. Moreover, these studies identified regulators of lateral root formation and regulators of pericycle founder cell identity. Integration of transcriptome datasets was useful for mechanistic comparisons between dicots and monocots during lateral root development. In addition, cell type-specific transcriptomics accelerated a deeper understanding of nitrate induced functional networks of lateral root formation in Arabidopsis and maize at the cellular level. In the future, it will be desirable to

\section{REFERENCES}

Alvarez, J. M., Riveras, E., Vidal, E. A., Gras, D. E., Contreras-López, O., Tamayo, K. P., et al. (2014). Systems approach identifies TGA1 and TGA4 transcription factors as important regulatory components of the nitrate response of Arabidopsis thaliana roots. Plant J. 80, 1-13. doi: 10.1111/tpj. 12618

Araya, T., Miyamoto, M., Wibowo, J., Suzuki, A., Kojima, S., Tsuchiya, Y. N., et al. (2014). CLE-CLAVATA1 peptide-receptor signaling module regulates the expansion of plant root systems in a nitrogen-dependent manner. Proc. Natl. Acad. Sci. U.S.A. 111, 2029-2034. doi: 10.1073/pnas.1319953111

Bell, J. K., and McCully, M. E. (1970). A histological study of lateral root initiation and development in Zea mays. Protoplasma 70, 179-205. doi: 10.1007/ BF01276979

Birnbaum, K., Shasha, D. E., Wang, J. Y., Jung, J. W., Lambert, G. M., Galbraith, D. W., et al. (2003). A gene expression map of the Arabidopsis root. Science 302:1956. doi: 10.1126/science. 1090022

Birnbaum, K. D. (2018). Power in numbers: single-cell RNA-Seq strategies to dissect complex tissues. Annu. Rev. Genet. 52, 203-221. doi: 10.1146/annurevgenet-120417-031247

Boudolf, V., Vlieghe, K., Beemster, G. T. S., Magyar, Z., Acosta, J. A. T., Maes, S., et al. (2004). The plant-specific cyclin-dependent kinase CDKB1;1 and transcription factor E2Fa-DPa control the balance of mitotically dividing and endoreduplicating cells in Arabidopsis. Plant Cell 16, 2683-2692. doi: 10.1105/ tpc. 104.024398

Brady, S. M., Orlando, D. A., Lee, J.-Y., Wang, J. Y., Koch, J., Dinneny, J. R., et al. (2007). A high-resolution root spatiotemporal map reveals dominant expression patterns. Science 318, 801-806. doi: 10.1126/science.1146265

Clowes, F. A. L. (1978). Chimeras and the origin of lateral root primordia in Zea mays. Ann. Bot. 42, 801-807. doi: 10.1093/oxfordjournals.aob.a085519

Coudert, Y., Le, V. A., Adam, H., Bès, M., Vignols, F., Jouannic, S., et al. (2015). Identification of CROWN ROOTLESS1-regulated genes in rice reveals specific and conserved elements of postembryonic root formation. New Phytol. 206, 243-254. doi: 10.1111/nph.13196

De Smet, I., Vassileva, V., de Rybel, B., Levesque, M. P., Grunewald, W., Van Damme, D., et al. (2008). Receptor-like kinase ACR4 restricts formative cell divisions in the Arabidopsis root. Science 322, 594-597. doi: 10.1126/science. 1160158 integrate in situ root visualization techniques such as micro $\mathrm{x}$-ray computer tomography with cell type-specific transcriptome analyses, although it is still challenging to apply FACS and LCM techniques to roots grown in natural soil environments. Single-cell RNA-seq (Birnbaum, 2018), will further increase the spatial and temporal resolution of cells involved in lateral root formation. This technique will for instance enable the identification of differences within pericycle cells that acquire lateral root founder cell identity and will reveal the details of the fine-tuned processes underlying lateral root organization and development.

\section{AUTHOR CONTRIBUTIONS}

$\mathrm{AK}, \mathrm{FH}$, and PY contributed to the writing of this review.

\section{FUNDING}

This work was supported by the Deutsche Forschungsgemeinschaft (DFG) grant no. YU 272/1-1 to PY and DFG grant no. HO2249/12-1 to FH.

De Veylder, L., Beeckman, T., Beemster, G. T. S., Krols, L., Terras, F., Landrieu, I., et al. (2001). Functional analysis of cyclin-dependent kinase inhibitors of Arabidopsis. Plant Cell 13, 1653-1668. doi: 10.1105/TPC.010087

Dembinsky, D., Woll, K., Saleem, M., Liu, Y., Fu, Y., Borsuk, L. A., et al. (2007). Transcriptomic and proteomic analyses of pericycle cells of the maize primary root. Plant Physiol. 145, 575-588. doi: 10.1104/pp.107.106203

Devaiah, B. N., Karthikeyan, A. S., and Raghothama, K. G. (2007). WRKY75 transcription factor is a modulator of phosphate acquisition and root development in Arabidopsis. Plant Physiol. 143, 1789-1801. doi: 10.1104/pp. 106.093971

Dolan, L., Janmaat, K., Willemsen, V., Linstead, P., Poethig, S., Roberts, K., et al. (1993). Cellular organisation of the Arabidopsis thaliana root. Development 119, 71-84.

Emmert-Buck, M. R., Bonner, R. F., Smith, P. D., Chuaqui, R. F., Zhuang, Z., Goldstein, S. R., et al. (1996). Laser capture microdissection. Science 274, 998-1001. doi: 10.1126/science.274.5289.998

Galbraith, D. W. (2010). Flow cytometry and fluorescence-activated cell sorting in plants: the past, present, and future. Biomédica 30, 61-69. doi: 10.7705/ biomedica.v30i0.824

Gälweiler, L., Guan, C., Müller, A., Wisman, E., Mendgen, K., Yephremov, A., et al. (1998). Regulation of polar auxin transport by AtPIN1 in Arabidopsis vascular tissue. Science 282, 2226-2230. doi: 10.1126/science.282.5397.2226

Gautam, V., and Sarkar, A. K. (2015). Laser assisted microdissection, an efficient technique to understand tissue specific gene expression patterns and functional genomics in plants. Mol. Biotechnol. 57, 299-308. doi: 10.1007/s12033-0149824-3

Gifford, M. L., Dean, A., Gutierrez, R. A., Coruzzi, G. M., and Birnbaum, K. D. (2008). Cell-specific nitrogen responses mediate developmental plasticity. Proc. Natl. Acad. Sci. U.S.A. 105, 803-808. doi: 10.1073/pnas.0709559105

Gutierrez, L., Bussell, J. D., Pǎcurar, D. I., Schwambach, J., Pǎcurar, M., and Bellini, C. (2009). Phenotypic plasticity of adventitious rooting in Arabidopsis is controlled by complex regulation of AUXIN RESPONSE FACTOR transcripts and microRNA abundance. Plant Cell 21, 3119-3132. doi: 10.1105/tpc.108. 064758

Gutjahr, C., Sawers, R. J., Marti, G., Andrés-Hernández, L., Yang, S. Y., Casieri, L., et al. (2015). Transcriptome diversity among rice root types during asymbiosis and interaction with arbuscular mycorrhizal fungi. Proc. Natl. Acad. Sci. U.S.A. 112, 6754-6759. doi: 10.1073/pnas. 1504142112 
Heim, M. A., Jakoby, M., Werber, M., Martin, C., Weisshaar, B., and Bailey, P. C. (2003). The basic Helix-Loop-Helix transcription factor family in plants: a genome-wide study of protein structure and functional diversity. Mol. Biol. Evol. 20, 735-747. doi: 10.1093/molbev/msg088

Hirota, A., Kato, T., Fukaki, H., Aida, M., and Tasaka, M. (2007). The auxinregulated AP2/EREBP gene PUCHI is required for morphogenesis in the early lateral root primordium of Arabidopsis. Plant Cell 19, 2156-2168. doi: 10.1105/ tpc.107.050674

Hochholdinger, F., and Zimmermann, R. (2008). Conserved and diverse mechanisms in root development. Curr. Opin. Plant Biol. 11, 70-74. doi: 10. 1016/j.pbi.2007.10.002

Hulett, H. R., Bonner, W. A., Barrett, J., and Herzenberg, L. A. (1969). Cell sorting: automated separation of mammalian cells as a function of intracellular fluorescence. Science 166, 747-749. doi: 10.1126/science.166.3906.747

Inukai, Y., Sakamoto, T., Ueguchi-Tanaka, M., Shibata, Y., Gomi, K., Umemura, I., et al. (2005). Crown rootless1, which is essential for crown root formation in rice, is a target of an AUXIN RESPONSE FACTOR in auxin signaling. Plant Cell 17, 1387-1396. doi: 10.1105/tpc.105.030981

Iyer-Pascuzzi, A. S., and Benfey, P. N. (2010). Fluorescence-activated cell sorting in plant developmental biology. Methods Mol. Biol. 655, 313-319. doi: 10.1007/ 978-1-60761-765-5_21

Jansen, L., Hollunder, J., Roberts, I., Forestan, C., Fonteyne, P., van Quickenborne, C., et al. (2013). Comparative transcriptomics as a tool for the identification of root branching genes in maize. Plant Biotechnol. J. 11, 1092-1102. doi: 10.1111/pbi.12104

Jiao, Y., Lori Tausta, S., Gandotra, N., Sun, N., Liu, T., Clay, N. K., et al. (2009). A transcriptome atlas of rice cell types uncovers cellular, functional and developmental hierarchies. Nat. Genet. 41, 258-263. doi: 10.1038/ng.282

Lavenus, J., Goh, T., Roberts, I., Guyomarc'h, S., Lucas, M., De Smet, I., et al. (2013). Lateral root development in Arabidopsis: fifty shades of auxin. Trends Plant Sci. 18, 450-458. doi: 10.1016/j.tplants.2013.04.006

Lee, H. W., Kim, N. Y., Lee, D. J., and Kim, J. (2009). LBD18/ASL20 regulates lateral root formation in combination with LBD16/ASL18 downstream of ARF7 and ARF19 in Arabidopsis. Plant Physiol. 151, 1377-1389. doi: 10.1104/pp.109. 143685

Ludwig, Y., and Hochholdinger, F. (2014). "Laser microdissection of plant cells," in Plant Cell Morphogenesis: Methods and Protocols, eds V. Žárský, and F. Cvrčková (Totowa, NJ: Humana Press), 249-258. doi: 10.1007/978-1-62703643-6_21

Lynch, J. P. (2011). Root phenes for enhanced soil exploration and phosphorus acquisition: tools for future crops. Plant Physiol. 156, 1041-1049. doi: 10.1104/ pp.111.175414

Lynch, J. P. (2013). Steep, cheap and deep: an ideotype to optimize water and N acquisition by maize root systems. Ann. Bot. 112, 347-357. doi: 10.1093/aob/ $\operatorname{mcs} 293$

Nelson, T., Tausta, S. L., Gandotra, N., and Liu, T. (2006). Laser microdissection of plant tissue: what you see is what you get. Annu. Rev. Plant Biol. 57, 181-201. doi: 10.1146/annurev.arplant.56.032604.144138

Okushima, Y., Fukaki, H., Onoda, M., Theologis, A., and Tasaka, M. (2007). ARF7 and ARF19 regulate lateral root formation via direct activation of LBD/ASL genes in Arabidopsis. Plant Cell 19, 118-130. doi: 10.1105/tpc.106. 047761

Parizot, B., Laplaze, L., Ricaud, L., Boucheron-Dubuisson, E., Bayle, V., Bonke, M., et al. (2008). Diarch symmetry of the vascular bundle in Arabidopsis root encompasses the pericycle and is reflected in distich lateral root initiation. Plant Physiol. 146, 140-148. doi: 10.1104/pp.107.107870

Parizot, B., Roberts, I., Raes, J., Beeckman, T., and De Smet, I. (2012). In silico analyses of pericycle cell populations reinforce their relation with associated vasculature in Arabidopsis. Philos. Trans. R. Soc. B 367, 1479-1488. doi: 10.1098/ rstb.2011.0227

Parizot, B., Rybel, B., and de Beeckman, T. (2010). VisuaLRTC: a new view on lateral root initiation by combining specific transcriptome data sets. Plant Physiol. 153, 34-40. doi: 10.1104/pp.109.148676

Péret, B., Desnos, T., Jost, R., Kanno, S., Berkowitz, O., and Nussaume, L. (2014). Root architecture responses: in search of phosphate. Plant Physiol. 166, 17131723. doi: 10.1104/pp.114.244541

Salleh, F. M., Evans, K., Goodall, B., Machin, H., Mowla, S. B., Mur, L. A. J., et al. (2012). A novel function for a redox-related LEA protein (SAG21/AtLEA5) in root development and biotic stress responses. Plant Cell Environ. 35, 418-429. doi: 10.1111/j.1365-3040.2011.02394.x

Schnable, P. S., Hochholdinger, F., and Nakazono, M. (2004). Global expression profiling applied to plant development. Curr. Opin. Plant Biol. 7, 50-56. doi: 10.1016/j.pbi.2003.11.001

Schnittger, A., Schöbinger, U., Stierhof, Y.-D., and Hülskamp, M. (2002). Ectopic B-type cyclin expression induces mitotic cycles in endoreduplicating Arabidopsis trichomes. Curr. Biol. 12, 415-420. doi: 10.1016/S0960-9822(02) 00693-0

Skirycz, A., Radziejwoski, A., Busch, W., Hannah, M. A., Czeszejko, J., Kwaśniewski, M., et al. (2008). The DOF transcription factor OBP1 is involved in cell cycle regulation in Arabidopsis thaliana. Plant J. 56, 779-792. doi: 10. 1111/j.1365-313X.2008.03641.x

Smith, D. L., and Fedoroff, N. V. (1995). LRP1, a gene expressed in lateral and adventitious root primordia of Arabidopsis. Plant Cell 7, 735-745. doi: 10.1105/ tpc.7.6.735

Stelpflug, S. C., Sekhon, R. S., Vaillancourt, B., Hirsch, C. N., Buell, C. R., de Leon, N., et al. (2016). An expanded maize gene expression atlas based on RNA sequencing and its use to explore root development. Plant Genome 9, 1-16. doi: 10.3835/plantgenome2015.04.0025

Takehisa, H., Sato, Y., Igarashi, M., Abiko, T., Antonio, B. A., Kamatsuki, K., et al. (2012). Genome-wide transcriptome dissection of the rice root system: implications for developmental and physiological functions. Plant J. 69, 126-140. doi: 10.1111/j.1365-313X.2011.04777.x

van Norman, J. M., Xuan, W., Beeckman, T., and Benfey, P. N. (2013). To branch or not to branch: the role of pre-patterning in lateral root formation. Development 140, 4301-4310. doi: 10.1242/dev.090548

Vanneste, S., De Rybel, B., Beemster, G. T. S., Ljung, K., De Smet, I., van Isterdael, G., et al. (2005). Cell cycle progression in the pericycle is not sufficient for SOLITARY ROOT/IAA14-mediated lateral root initiation in Arabidopsis thaliana. Plant Cell 17, 3035-3050. doi: 10.1105/tpc.105. 035493

Vidal, E. A., Araus, V., Lu, C., Parry, G., Green, P. J., Coruzzi, G. M., et al. (2010). Nitrate-responsive miR393/AFB3 regulatory module controls root system architecture in Arabidopsis thaliana. Proc. Natl. Acad. Sci. U.S.A. 107, 4477-4482. doi: 10.1073/pnas.0909571107

Vidal, E. A., Moyano, T. C., Riveras, E., Contreras-López, O., and Gutiérrez, R. A. (2013). Systems approaches map regulatory networks downstream of the auxin receptor AFB3 in the nitrate response of Arabidopsis thaliana roots. Proc. Natl. Acad. Sci. U.S.A. 110, 12840-12845. doi: 10.1073/pnas.1310937110

Walker, L., Boddington, C., Jenkins, D., Wang, Y., Grønlund, J. T., Hulsmans, J., et al. (2017). Changes in gene expression in space and time orchestrate environmentally mediated shaping of root architecture. Plant Cell 29, 2393-2412. doi: 10.1105/tpc.16.00961

Wang, G., Kong, H., Sun, Y., Zhang, X., Zhang, W., Altman, N., et al. (2004). Genome-wide analysis of the cyclin family in Arabidopsis and comparative phylogenetic analysis of plant cyclin-like proteins. Plant Physiol. 135, 1084-1099. doi: 10.1104/pp.104.040436

Wang, J., Hu, H., Wang, G., Li, J., Chen, J., and Wu, P. (2009). Expression of PIN genes in rice (Oryza sativa L.): tissue specificity and regulation by hormones. Mol. Plant 2, 823-831. doi: 10.1093/mp/ssp023

Woll, K., Borsuk, L. A., Stransky, H., Nettleton, D., Schnable, P. S., and Hochholdinger, F. (2005). Isolation, characterization, and pericycle-specific transcriptome analyses of the novel maize lateral and seminal root initiation mutant rum1. Plant Physiol. 139, 1255-1267. doi: 10.1104/pp.105. 067330

Yu, P., Eggert, K., Wirén, N., von Li, C., and Hochholdinger, F. (2015). Cell typespecific gene expression analyses by RNA sequencing reveal local high nitratetriggered lateral root initiation in shoot-borne roots of maize by modulating auxin-related cell cycle regulation. Plant Physiol. 169, 690-704. doi: 10.1104/pp. 15.00888

Yu, P., Baldauf, J. A., Lithio, A., Marcon, C., Nettleton, D., Li, C., et al. (2016a). Root type-specific reprogramming of maize pericycle transcriptomes by local high nitrate results in disparate lateral root branching patterns. Plant Physiol. 170, 1783-1798. doi: 10.1104/pp.15.01885

Yu, P., Gutjahr, C., Li, C., and Hochholdinger, F. (2016b). Genetic control of lateral root formation in cereals. Trends Plant Sci. 21, 951-961. doi: 10.1016/j.tplants. 2016.07.011 
Yu, P., Wang, C., Baldauf, J. A., Tai, H., Gutjahr, C., Hochholdinger, F., et al. (2018). Root type and soil phosphate determine the taxonomic landscape of colonizing fungi and the transcriptome of field-grown maize roots. New Phytol. 217, 1240-1253. doi: 10.1111/nph.14893

Zhang, Y., Paschold, A., Marcon, C., Liu, S., Tai, H., Nestler, J., et al. (2014). The Aux/IAA gene ruml involved in seminal and lateral root formation controls vascular patterning in maize (Zea mays L.) primary roots. J. Exp. Bot. 65, 4919-4930. doi: 10.1093/jxb/eru249

Zhao, H., Ma, T., Wang, X., Deng, Y., Ma, H., Zhang, R., et al. (2015). OsAUX1 controls lateral root initiation in rice (Oryza sativa L.). Plant Cell Environ. 38, 2208-2222. doi: 10.1111/pce.12467
Conflict of Interest Statement: The authors declare that the research was conducted in the absence of any commercial or financial relationships that could be construed as a potential conflict of interest.

Copyright (c) $2019 \mathrm{Kortz}$, Hochholdinger and Yu. This is an open-access article distributed under the terms of the Creative Commons Attribution License (CC BY). The use, distribution or reproduction in other forums is permitted, provided the original author(s) and the copyright owner(s) are credited and that the original publication in this journal is cited, in accordance with accepted academic practice. No use, distribution or reproduction is permitted which does not comply with these terms. 